\title{
Significance of Loanwords
}

\author{
Xulai Gao* \\ French Department, School of Western Languages, Harbin Normal University, China
}

*Corresponding author: Xulai Gao, xulaigao@163.com

Copyright: (C) 2022 Author(s). This is an open-access article distributed under the terms of the Creative Commons Attribution License (CC BY 4.0), permitting distribution and reproduction in any medium, provided the original work is cited.

\begin{abstract}
The existence of loanwords, whose emergence has a profound connection with cultural globalization, is undoubtedly obliged to be valued. This phenomenon of linguistic integration can be appreciated everywhere in all major languages which are still widely spoken. However, this has led to the resistance of some nationalist linguists, who advocate the purity of their respective languages. Nevertheless, the purported "linguistic purity" is a false concept unquestionably. The lexical interflow is undoubtedly of irreplaceable significance, which can never be denied. Cultural diversity is absolutely the unchangeable mainstream. With this mindset, the world will be harmonious with a sense of freedom to bathe in light of tolerance and empathy.
\end{abstract}

Keywords: Linguistics; Lexicology; Language contact; Etymology; Cultural globalization

Online publication: January 12, 2022

It has long since been well-witnessed that an upward trend of linguistic integration has emerged along with the ineluctable presence of globalization, which is certainly, to a large extent, resulting in the further elimination of superfluous collisions deprived from the difference in ideologies. The appearance of loanwords, and its destined indigenous process, certainly consists, as a long-lasting observed phenomenon, in this natural integration. Confronting the unfriendly queries of those opposed contestants who believe that loanwords ought not to be embraced in their respective native languages, rational points of view held by exoteric linguists are bound to be brought forward in a steadfast and persuasive way, considering its undeniable positiveness, but unsatisfactorily under the circumstance that the contemporary cultural estrangement is yet to diminish. Nevertheless, without doubt has the world, where we all live, been transformed into a community with a shared future for mankind. Therefore, loanwords are certainly of great significance in whichever language existing in the world.

"Loanwords are motivated in two ways, by prestige and by the need to fill in blanks ${ }^{[1]}$," said Hockett, a respectable linguist specialized in the domain of language contact, and right in which it is reasonable to ascribe the English application of this essay to the first motivation - prestige. Following the postwar international power layout, English has gradually become the sole dominance across the globe, given that the absolute superiority had been firmly taken by English-speaking countries, in terms of economy, military, and especially culture. As an inevitable consequence, the prestige of superpowers has successfully acted on the extensive acceptance of Anglo-Saxon vocabularies on a world scale. Although certain nationalist scholars argue that this process of integration is overwhelmingly destructive for the protection of those relatively uncommon languages spoken by the minority, evidence has shown that loanwords out of prestige are mostly beneficial, owing to their irreplaceable assistance in constructing a more complete linguistic system, in which ordinary people are able to recognize the other side of the world in a better way. It is true that forced ideological instillation is potential, but there are many refreshing and unexpectedly 
advantageous aspects on the intellectual level coming from completely different places, which are factually promoting the cultural connection and cultivating people's mindset to view the world as a "global village." Meanwhile, borrowings of prestige make it more convenient to access to other "prestigious" individuals in a positive way. It is absolutely impractical to be outstanding on earth while being incapable of realizing how formidable the burgeoning counterparts can be in reality. In like manners, it is equally available to utilize the realization of this massive gap for marching toward a better platform. No one would like to strive hard for brilliance if permanently subdued in the "isothermal layer."

Perfection or completeness does not exist but the process of pursuing it accelerates the purging of those disturbing defects, which brings to the second point - the need to fill in blanks, serving as the paramount motivation to maintain the legitimate status of loanwords. After all, borrowing is for certain the most important method of vocabulary development in languages ${ }^{[2]}$. Obviously, there are objects that do not exist in other countries speaking different languages or those that discovered them relatively late. In that case, borrowings naturally take place. For instance, ancient occidentals had never sipped green tea until it was introduced by Chinese merchants, for which European languages had to adopt the loanword "tea," whose original character is "te" in Amoy dialect ${ }^{[3]}$; however, with the exception of Slavonic languages, in which "tea" is called "chai" as northern Chinese dialects had a more frequent contact with them. Furthermore, several abstract notions, which have been invented by people using other languages, also rely on the application of loanwords when conveyed in the native language. For example, "Tao," transliterated from Chinese, is an ancient philosophy epitomizing loads of different moralities and doctrines. It is diametrically impractical to convey this concept with existing English words due to cultural differences. In like manners, "Xiao" is concurrently not supposed to be translated into "filial," given that Orientals firmly adhere to a dissimilar family value. At this point, people have to stay open when facing loanwords while acknowledging their necessity for "filling in blanks." More crucially, cultural backgrounds differ on multiple dimensions because of which subtle differences in implications cannot be neglected. "Algebra" from Arabic refers to a specific subject with numerous complicated calculations, whereas "calculation" does not equate to "algebra." "Kimchi" from Korean is factually a pickled dish containing cabbages and onions ${ }^{[4]}$, but it does not correspond with "pickles" in western cuisine. As a French proverb says, "use makes master", widely are loanwords used today with their definite practicability, granted by their respective unique cultures as well as languages. Undoubtedly, loanwords spread for solid reasons.

Reversely, some believe that lexical borrowing is a microcosm of virulent hegemony, while mistaking "interflow" for unidirectional infusion. However, cultural communication should not be considered as something dangerous. As a famous saying of Tagore goes, "The English colonized us, but we colonized the English language." The courage to accept a strong and different culture is an inevitable procedure in rebuilding national confidence in the world which belongs to globalization. However, there are still several linguists who disappointingly devote themselves to the "purity" of their native languages, which is unquestionably a false concept. Facing the prestige of English, countries that speak different languages should not interdict the process of borrowings from English language but properly utilize English vocabularies based on their self-development needs ${ }^{[5]}$. Thousands of years ago, Greece, the ancient place, which is regarded as the wellspring of occidental civilizations, largely enriched its language with oriental loanwords, enabling themselves to secure wholly conversations with merchants from other places, objectively having burgeoned the development of Greek commerce, which later turned to result in a number of prosperous poleis. Hence, it is utterly incorrect to wipe out this "ocean spirit" which has been proven indeed successful.

Loanwords can be seen everywhere in all the major languages, which are still spoken nowadays. This situation cannot last unless lexical interflow is merited. Most realistically, the application of loanwords from foreign languages tends to play a role of motivator for civilian and academic communication among 
those who speak different languages. It is easy for a non-English speaker to understand "club" and "party," since these two words have been borrowed by almost every major language which exists today. Loanwords have indeed contributed to the situation where someone delivers greetings to a random foreign stranger, saying "Let's party." That sort of scenario is certainly what one should look forward to. In a nutshell, being conservative while resisting to the world's connected nature is definitely noxious in the 21 st century. Diversity is absolutely the unchangeable mainstream. With this mindset, the world will be harmonious with a sense of freedom to bathe in light of tolerance and empathy.

\section{Disclosure statement}

The author declares that there is no conflict of interest.

\section{References}

[1] Hockett CF, 1958, A Course in Modern Linguistics, Linguistic Society, United States, 439.

[2] Chang H, 2001, Loanwords in Italian and Their Significant Effects, Academic Journal, University of Sun Yat-sen, 45.

[3] Onions CT, 1994, The Oxford Dictionary of English Etymology, Oxford University Press.

[4] 2022, Etymology. Dictionary.com, Random House, Inc. https://www.dictionary.com/browse/kimch i? $\mathrm{s}=\mathrm{t}$

[5] Zheng Z, Zhang S, 2008, Languge Purity Under the Context of Globalization. Journal of Hebei University Hebei University Press, 33(5): 60. 